\title{
Striking a balance between Intellectual Property Protection of Traditional Knowledge, Cultural Preservation and Access to Knowledge*
}

\section{Professor Pamela Andanda,}

School of Law, University of the Witwatersrand, Johannesburg Private Bag 3, Wits 2050; E-mail: Pamela.Andanda@wits.ac.za and Visiting Research Fellow, World Trade Institute, Bern

\begin{abstract}
Protecting traditional knowledge through the intellectual property (IP) regime performs the important function of preventing third parties from using the knowledge inappropriately. However, apart from being inaccessible to most holders of traditional knowledge (TK), the regime does not necessarily guarantee the preservation or safeguarding the knowledge. These concerns call for a consideration of avenues that can be used, particularly at policy making level, to strike a balance between protecting TK through the IP regime and ensuring cultural preservation and access to knowledge. This paper highlights the main challenges that are involved in striking this balance. Apart from utilizing available literature on these challenges, the main suggestions from the World Intellectual Property Organization, Intergovernmental Committee on Intellectual Property and Genetic Resources, Traditional Knowledge and Folklore (the IGC) are analyzed with a view to proposing directions that can help to improve the manner in which TK is protected through IP.
\end{abstract}

Keywords: access to knowledge, cultural preservation, intellectual property, traditional knowledge, sui generis protection

\footnotetext{
* An early version of this article was presented at an international conference on Intellectual Property Law and Development - the Road Ahead; Traditional Knowledge and Access to Knowledge, which was organized by the World Intellectual Property Organization (WIPO), in cooperation with the Comparative Legal Research Center, Ono Academic College and the Israel Ministry of Foreign Affairs in Tel Aviv, $24^{\text {th }}$ to $25^{\text {th }}$ October 2011.
}

This article has been accepted for publication in the Journal of intellectual Property Rights, vol. 17, November 2012. 


\section{Introduction}

Preserving and safeguarding TK implies 'identification, documentation, transmission, revitalization and promotion of cultural heritage to ensure its maintenance and viability. ${ }^{1}$ It has however been pointed out, and correctly so, that the process of preserving and safeguarding TK 'can run the risk of unintentionally placing [traditional cultural expressions] TCEs in the "public domain'; thus leaving others free to use them against the wishes of the original community. ${ }^{, 1}$ Wendland has correctly observed that the very process of preservation of traditional cultural expressions can trigger concerns about their lack of legal protection against misappropriation and misuse. ${ }^{2}$ This is the reason why IP protection does not necessarily guarantee the preservation or safeguarding of TK and access to knowledge. This reason can also be attributed to the fact that TK has both economic and moral value.

The protection of TK is however distinguishable from the efforts that have been made to promote and safeguard TK. Promoting and safeguarding TK are mostly relevant when aspects of TK such as photographs, sound recordings, films and manuscripts are documented and preserved in libraries and museums. ${ }^{3}$ These two institutions play an important role in promoting and safeguarding TK, thus fostering access to knowledge, but their role still raises the concern that they may unintentionally place TK in the public domain. It is this concern that brings the need for protection, in the legal sense, into play. Protection is used in this paper in the same sense that the World Intellectual Property Organization (WIPO) has used it in the context of TCEs, viz., 'protection of the creativity and distinctiveness inherent in TCEs against unauthorized or illegitimate use by third parties, including commercial misappropriation, misuse, misrepresentation and use that is derogatory or offensive. ${ }^{3}$

The unintended consequences of preserving TK clearly illustrate the impact of the existing dichotomy between the protection of property rights by IP and the need to respect the moral and material interests of those who create and maintain TK, as human rights. ${ }^{4}$ It is therefore not surprising that a number of concerns have recently been raised regarding the protection of TK using the IP regime. According to WIPO, two concerns by member states are: 'first, the availability of intellectual property protection for traditional knowledge holders, ... and, second, the acquisition by parties other than the traditional knowledge holders of intellectual 
property rights over traditional knowledge-based creations and innovations. ${ }^{, 5}$ These concerns have led to request by member states 'that traditional knowledge holders should be able to protect their knowledge....and that parties other than traditional knowledge holders should not be able to protect unmodified traditional knowledge. ${ }^{6}$ These requests by member states raise two very practical questions. First, is the IP regime in its current form capable of protecting TK in an adequate manner? Adequacy in this context would encompass both protection and preservation. Secondly, which means can be used to ensure that third parties do not protect unmodified traditional knowledge? The second issue is closely linked to the need to ensure cultural preservation and access to knowledge, which are important in attempting to strike the balance that TK holders are yearning for.

Since this paper aims at making recommendations at policymaking level, it does not focus on discussing specific types of TK. It utilizes reports from the IGC's ongoing negotiations since this is the main intergovernmental organization, which has attempted to address TK holders' concerns in a more systematic manner and its reports are more accessible. Although most extensive discussions have taken place within the IGC, it must be noted that these discussions are more relevant for norm making. This is evident, for instance, from the manner in which the IGC has focused on understanding national experiences, lessons learned and common elements from the existing national sui generis measures and laws for protecting TK. ${ }^{7}$ This notwithstanding, the discussions are vital for developing a policy framework for the protection of TK at national levels since specific laws at this level would benefit a great deal from a sound policy framework.

The IGC's approach is in line with its mandate as a forum for discussion among WIPO's member states and is in accordance with the four tasks, which WIPO's general assembly set out for the IGC. ${ }^{8}$ First, the IGC is entrusted with the task of clarifying terminological and conceptual issues in relation to the subject matter that should be protected. Secondly, it has to develop new standards for protecting TK that is not protected by the existing intellectual property tools by elaborating an international framework for such protection. Thirdly, it has to integrate TK into procedures of intellectual property offices and provide legal assistance with the documentation of TK. Fourthly, it has to facilitate access to the intellectual property system, so that TK holders can enforce their rights under the intellectual property system. It is evident from these four tasks that 
the IGC as a forum is not mandated with law-making as such. The tasks enable the IGC to establish norms that can be utilized for policy making at the regional and national levels.

\section{Protecting TK through intellectual property}

The protection of TK through IP prevents unwanted use by others especially culturally offensive and demeaning use. Consequently, 'communities may wish to gain IP protection in order to actively exercise IP rights to prevent the use and commercialization of their cultural heritage and TCEs by others, including culturally offensive or demeaning use.' ${ }^{1}$ The fact that 'the progressive appropriation of TK through intellectual property rights also has an impact on the ownership of $\mathrm{TK}^{, 9}$ should not however be overlooked. This is so in so far as resources that are communally owned by TK holders may end up being owned exclusively by individuals thus excluding TK holders from using such resources.

Meaningful protection of TK, as Munzer and Raustiala have pointed out, 'will require a major deviation from established legal as well as philosophical doctrine. ${ }^{10}$ This observation essentially means that there are challenges involved in protecting TK through IP.

\section{Challenges that are involved in protecting TK}

Two challenges are worth noting in attempting to protect TK through IP: First, there is an underlying problem in so far as 'the IP needs of TK holders are shaped by their contact with the formal IP systems on the one hand and informal IP regimes that prevail in their societies and communities on the other... ${ }^{11}$ This has correctly been termed as the 'cross-cultural problem,11 and it is referred to in this paper as the 'cross-cultural' challenge.

The informal IP regimes consist of 'diverse but stable societal structures which regulate the flow of knowledge and innovations. ${ }^{11}$ The IGC has acknowledged this fact in its proposal that calls for 'understanding the interfaces between the formal intellectual property system and customary legal systems which apply to traditional knowledge in local and indigenous communities' as one of the conceptual questions that 'need [s] to be addressed in order to make systems and standards for the protection of traditional knowledge clear, practical and accessible to traditional knowledge holders. ${ }^{, 6}$ One notable feature of the societal structures that govern TK in a manner that creates incompatibility with the formal IP system is collective ownership. Collective ownership is complex in the sense that the individuals may hold the knowledge for 
their own use but 'ownership is often subject to customary law and practice and based on the collective consent of the community. ${ }^{12}$ This complexity explains why one of the avenues that is being explored within the formal IP system, which is discussed later in this paper, is the procurement of prior informed consent of the community when TK is used by patent applicants.

The second challenge is that the IP system is 'based on document-intensive, codified and governmentally administered structures and procedures. ${ }^{, 6}$ This attribute of the IP system makes it inaccessible to TK holders who may find the requisite formalities difficult to comply with and the costs may equally be prohibitive. A useful suggestion that has been put forward in order to make the system accessible is that IP offices need to know of the existence of TK and this is only possible if the local community of TK holders establish a working relationship with such offices. ${ }^{13}$ This suggestion can work if TK is documented and IP offices are granted access to the database so that the information can be used for defending the rights of TK holders against inappropriate use by third parties. The suggestion does not however address the other problems that TK holder may have with the formal IP system such as elements of incompatibility and prohibitive costs of filing their own applications.

\section{The main shortcomings of the IP system in protecting TK and fostering access to knowledge}

The shortcomings are essentially the results of the inherent differences between IP and TK. Highlighting the shortcoming of the IP system does not imply that it is incapable of being used to protect TK. The conceptual and practical challenges that have been identified in literature are the main hurdles that need to be overcome in order to strike a balance in protecting and preserving TK. These are discussed below.

\section{Challenges related to the principles and objectives of TK protection}

The IGC confirmed that member states have articulated the need to respect and preserve traditional knowledge systems. ${ }^{6}$ This echoes concerns that have been identified in literature that the IP system is too narrow for TK holders who desire to protect their entire culture (not isolated manifestations) and to have some control over the use of knowledge that originates from their culture. $^{14}$ These concerns confirm the existence of a divergence between property rights and human rights approach in dealing with TK. In this regard, there is a clear need for striking a proper balance between public and private interests. Member states have equally emphasized the 
need to ensure fair and equitable distribution of benefits arising from the use of traditional knowledge. ${ }^{6}$

\section{The 'cross-cultural' challenge}

As noted earlier, the 'cross-cultural' challenge arises from the fact that the needs of TK holders are simultaneously governed by the formal IP systems and the informal IP regimes that prevail in their societies and communities. ${ }^{11}$ The IGC noted that this presents a conceptual issue, which requires 'understanding the interfaces between the formal intellectual property system and customary legal systems which apply to traditional knowledge in local and indigenous communities'. ${ }^{15}$ This translates into what Dutfield has accurately described as practical and conceptual challenges that are involved in protecting TK using the IP regime. ${ }^{16}$ These challenges are worth highlighting at this stage in order to lay the foundation for exploring further avenues that may be used to protect TK in a more balanced manner.

The IP system focuses more on individual creations such that, as Dutfield correctly notes, copyright law's 'notion of authorship is a problematic concept in many traditional societies' and 'qualified person' requirement is practically inconvenient to 'collective groups.' ${ }^{16}$ It is also notable that patent law's requirement of naming an inventor can be an obstacle for TK applicants. The complication arises from the fact that traditional creativity is marked by a dynamic interplay between collective and individual creativity. ${ }^{2}$ The following Statement by Jacob Simet, Executive Director of the National Culture Commission, Port Moresby, Papua New Guinea, which is quoted in the WIPO Report on Fact-Finding Missions, clearly illustrate this point:

"We have had songs, traditional knowledge and so on for hundreds of years. There was no doubt as to who originally owned them - they were originally owned by one person, who later passed them on to his or her clan. There were clear customary laws regarding the right to use the songs and the knowledge. There was no problem in the past. Why are there problems now? We should begin with communities, and see how they protected their cultural expressions and knowledge. Then we should use the same customary tools or tools adapted from them". ${ }^{11}$ 
The suggestions that are given in the above quote essentially require taking the TK holders' customary laws into consideration when the IP system is used for protecting TK. A suitable working definition of customary law in this context has been provided by the Convention of Biological Diversity's secretariat as 'written and/or unwritten (including oral traditions) rules, usages, customs, practices and beliefs, traditionally and continually recognized and accepted as legal requirements or obligatory rules of conduct and consequently treated as if they were laws, by the group concerned. ${ }^{, 17}$

The need for 'developing methods to deal with the collectivity of creation, innovation and ownership in certain traditional knowledge systems', ${ }^{6}$ which has been acknowledged by WIPO is equally relevant in light of these suggestions. In this regard, policy makers need to reckon with Gervais' insightful suggestion that 'we need to continue to build, and then cross, a cultural bridge to explain current forms of intellectual property to holders of traditional knowledge., 18 Building such a bridge entails making an effort to incorporate appropriate customs of the TK holders into any alternative system that may be developed to protect TK.

\section{Normative challenge}

The practical and conceptual challenges that are mentioned above arise from the tension, which results from the divergent aims of IP protection and TK protection. For instance, one of the aims of IP protection is 'to strike a balance between the public domain and private monopolies. ${ }^{10} \mathrm{In}$ view of this aim, Munzer and Raustiala argue that 'the expansive protection of TK would, with some qualifications, remove what is now in the public domain from that domain. ${ }^{, 10}$

The above approach is problematic and presents a conflict with the communities' interests particularly with regard to ownership of TK. Besides, it raises a conceptual issue; public availability does not necessarily mean 'within public domain' in the sense that what the communities have made publicly available does not automatically fall within public domain. ${ }^{19}$ In this regard, Correa has correctly argued that TK `may not be considered freely available and usable by any party. Hence, it cannot be regarded as integrated with the public domain in the sense of information free to be used and consumed. ${ }^{4}$ Although Munzer and Raustiala find expansive protection of TK problematic, they however concede that public domain is not simply an open-access resource from which either individuals or groups may, without normative let or hindrance, withdraw units of the resource. ${ }^{10}$ Reference to 'normative let or hindrance' in this 
context seems to accommodate the idea of reckoning with the TK holders' customary laws and other social structures that are in place to ensure the preservation of culture and access to knowledge.

A detailed discussion of the different views on the public domain is beyond the limited scope of this paper. It however suffices to mention some of the key concerns about the IP regime's treatment of TK as being mostly within the public domain. Cottier and Panizzon have for instance observed that 'at the heart of the problem is that traditional knowledge has been considered as a matter in the public domain,... accessible and exploitable by the public at large, and... by any company interested in the information. ${ }^{, 20}$ Authors like Correa have noted that the 'differing interpretations of the scope of the public domain in relation to traditional knowledge have been one of the hurdles confronting the still-ongoing debates about protection of and compensation for traditional knowledge. ${ }^{4}$

A very interesting and thought-provoking point which has been raised by Forero-Pineda is that information is not in the public domain by its public good nature or even by its governmental origin but as the result of a network of formal and informal social agreements, explicit or implicit but entrenched in common law and in the culture of a society. ${ }^{21}$ This point is closely related to the cross cultural challenge that was mentioned earlier. The implication is that information should not simply be considered to be in the public domain as defined by the IP regime but the common law and culture of the TK holders should equally come into play in defining the information, which falls within the public domain.

The time limit or restricted time for protection, which is applied in the IP regime, reflects the underlying approach to what falls within the public domain and this is problematic for TK holders as well. For instance, 'folkloric expressions that are important elements of people's cultural identity' would require permanent protection while copyright protection has an expiry period. $^{16}$

The shortcomings that are discussed in this section definitely call for an intervention. The following conclusion by Dutfield equally reinforces such a need:

[Intellectual property rights (IPRs)] 'don't appear to provide many opportunities of which traditional peoples and communities can avail themselves' i.e., framing the issue 
of TK protection in the discourse of western IPRs don't go very far unless it's embedded in much broad-based negotiations between traditional peoples and communities, national governments, businesses and scientists in which the most fundamental concerns of these people and communities, such as self-determination (for indigenous people), territorial rights and human rights are openly and comprehensively addressed. ${ }^{, 16}$

This conclusion opens space for discussing current efforts that are used to safeguard TK within the IP system.

\section{Efforts geared towards protecting TK}

There are currently two broad approaches to protecting TK, which are under consideration; exploring further avenues within the formal IP system and developing a separate sui generis system for protecting TK. Both approaches are being used because TK holders don't find the IP system suitable for protecting and preserving TK. However, WIPO`s fact finding mission established that one short term option that holders of TK suggested was that attention be focused on the extent to which the present IP system can be used to protect TK. ${ }^{11}$ WIPO's way forward with this suggestion is 'testing [the] use of present IP system for TK protection, through practical and technical community-level pilot projects, case studies, training and awareness-raising. ${ }^{11}$

A detailed discussion of the separate sui generis system is beyond the limited scope of this paper, which seeks to assess the extent to which IP protection can foster cultural preservation and access to knowledge. It however suffices to mention some ongoing developments on this system that can influence policy making, particularly in view of the fact that TK holders have suggested testing the present IP system as a short term option and several TK holders and others have expressed the belief 'that in the longer term new norms would be needed, as the IP system would not meet all the needs of indigenous peoples and other TK holders. As such, a separate system of rights may be needed.' ${ }^{11}$ Close collaboration between TK holders and their communities is mandatory in designing the separate system. ${ }^{16}$ This approach is vital for accommodating diverse jurisprudence at the national level. 
Sui generis system of protection

Sui generis protection entails an acquisition of an alternative right that is separate from the rights that are recognized under the formal IP system, by the TK holders, as provided for under the system. Discussions about using positive protection for TK using a sui generis system started during the third session of the IGC, in 2002, when WIPO prepared a paper on 'elements of a sui generis system for the protection of $\mathrm{TK}^{22}$ The preparation of this paper was preceded by suggestions during the second session in 2001, led by the African group, that WIPO should determine which categories of traditional knowledge could be protected under existing legislation and develop new sui generis mechanisms in order to ensure adequate protection. ${ }^{23}$

During the discussions at the IGC, it has been recognized that the existing IP regime is inadequate for protecting the holistic character of TK. ${ }^{24}$ This recognition has led to calls, particularly during the fifth session of the IGC, for a separate system that can specifically protect TK (sui generis protection). ${ }^{25} \mathrm{~A}$ draft of the legal instrument has been prepared and was presented at the twenty first session of the IGC. ${ }^{26}$ The draft text is still a work in progress that is being discussed under WIPO's mandate for 2012/2013, which could lead to an international legal instrument which will ensure the effective protection of genetic resources, TK and TCEs. ${ }^{27}$

It has to be emphasized that the legal instrument will not contain legally binding rules that member states are obliged to follow in view of the IGC's limited mandate, which I have already explained in this paper. The non-binding nature of the instrument is evident from looking at the nature and scope of the draft text, which stipulates policy objectives and general guiding principles for member states. The articles of the text equally provide for very broad issues such as the subject matter for protection, scope of protection, sanctions, remedies and exercise of rights, disclosure requirements, administration of rights, application of collective rights, exceptions and limitations, term of protection and formalities. ${ }^{28}$ Additional steps will need to be taken with a view to negotiating a legally binding treaty based on the draft articles, which have been prepared by the IGC.

Apart from the ongoing negotiations at the IGC, it has to be noted that the United Nations (UN) General Assembly adopted the UN Declaration on the Rights of indigenous Peoples on $17^{\text {th }}$ September 2007, which can be used for sui generis protection of TK. The Declaration focuses on the rights of indigenous people but it has provisions, specifically Articles 11 and 31, which can 
be used for protecting TK. Article 11(1) provides that indigenous peoples have the right to practise and revitalize their cultural traditions and customs', while Article 11(2) obliges states to provide redress through effective mechanisms with respect to indigenous peoples' cultural, intellectual, religious and spiritual property taken without their free, prior and informed consent or in violation of their laws, traditions and customs. The protection of the holistic character of TK, which TK holders are yearning for, is clearly envisaged in this Article. Article 31 is even more comprehensive in its scope. Article 31(1) provides, in part, that indigenous peoples 'have the right to maintain, control, protect and develop their intellectual property over such cultural heritage, traditional knowledge, and traditional cultural expressions.' Article 31(2) obliges states to use effective measures, in conjunction with indigenous peoples, to recognize and protect the exercise of these rights.

The Declaration is a non-binding legal instrument and as such the reach of these Articles depends on the establishment of sui generis protection systems at the national level. This is the case because; the Articles leave the obligation of protecting TK to states. As such, the concern, which has been raised by McManis and Teran, ${ }^{29}$ that the protection of TK depends on the political will of governments to recognize the rights needs to be addressed particularly through the ongoing negotiations at the IGC. This need was pointed out by the delegation of Brazil during the fifth session (see paragraph 136 of the Report ${ }^{25}$ ) when it was suggested that the IGC's mandate should include norm setting and should prepare grounds for the negotiation of an international, legally binding treaty of sui generis protection. The delegation equally called on the IGC to coordinate with other international organizations that are working in the same area.

There is an urgent need for a legally binding international instrument in view of the fact that non-binding instruments, such as the UN Declaration on the Rights of indigenous Peoples is too weak to provide adequate protection of TK. Regional ${ }^{30}$ and national (see Verma for a detailed survey of national developments), ${ }^{24}$ initiatives for the development of a sui generis system are already at an advanced stage but the main concern, as Verma correctly argues, is that these initiatives 'have been constructed on the basis of the special needs of individual countries, depending upon their cultural and political conditions...[whereas] Any international regime on the protection of TK has to take into account this diversity, prompted by individual countries' needs and perceptions towards TK, and also address the more formidable aspects of its enforceability and monitoring. ${ }^{24}$ Verma's arguments underscore the relevance of the ongoing 
negotiations at the IGC that are geared towards the development of an international legal instrument.

Enforceability and monitoring are essential elements, which should be incorporated into the envisaged international legal instrument due to the fact that TK is currently used in transactions and activities that are globalized such as trade and innovation. In this regard, exclusive reliance on initiatives at national and regional levels would be inadequate to protect TK.

Developing an international sui generis system for protecting TK however raises controversies. First, it may end up hindering access to affordable knowledge goods even for indigenous and local communities. ${ }^{31}$ This is likely to happen if the system is not flexible enough to accommodate the local needs of individual countries. ${ }^{24}$ Secondly, there is diversity of views on the nature of the envisaged regime ${ }^{24}$ such that Oseitutu has suggested that alternative means should be sought for protecting TK if the sui generis system reduces access because such restriction is not the best defence against misappropriation. ${ }^{31}$ The suggestion by the delegation of Brazil, which I mentioned earlier, that the IGC coordinates with other international organizations that are working on the same issue, is the best way forward in ensuring that these controversies are adequately addressed in developing the international legal instrument.

\section{Exploring further avenues within the formal IP system}

Specific means within the IP system that are currently being used to protect TK are the creation of TK databases and registries, including disclosure of origin and prior informed consent requirement in patent applications, joint inventorship and introduction of petty patents. These means have been proposed by the IGC and they are equally identified in current literature as possible ways of accommodating the needs of TK holders. The details are discussed below.

\section{Creation of TK databases and registries}

The relevant task for member states, which has been suggested by the IGC is that '[m]ember States may wish to consider revising existing criteria and developing new criteria which would allow the effective integration of traditional knowledge documentation into searchable prior art. $^{32}$ This requires the establishment of TK databases that are 'compiled and systematically arranged to make [them] accessible to patent examination offices'. 33 
Databases and registries have been created in countries such as china, India and Venezuela for defensive and positive protection of TK. Defensive protection relates to what is commonly known in literature as 'defensive disclosure' in respect of which 'information or documentation [is] intentionally made available to the public as prior art in order to render any subsequent claims of invention or discovery ineligible for a patent. ${ }^{34}$ Positive protection entails filing a patent application with a view to protecting TK. ${ }^{10}$

In China, the Traditional Chinese Medicine (TCM) Patent Database has been compiled by the State Intellectual Property Office (SIPO) to meet the needs of patent examination. It contains bibliographic records and TCM formulas. ${ }^{35}$

India's Traditional Knowledge Digital Library (TKDL) warrants special mention and description since it is currently accessible to a number of international patent offices and provides a good example of how it can aid the IP system to prevent unwanted use of TK by third parties. TKDL is a collaborative project of the council of Scientific and Industrial Research (CSIR), Ministry of Science and Technology and Department of AYUSH (Ayuveda, Yoga and naturopathy, Unani, Siddha and Homeopathy) as well as the Ministry of Health and Family Welfare, and is being implemented at CSIR. ${ }^{36}$ The project was initiated in the year 2001 for purposes of providing information on $\mathrm{TK}$, in languages and format that patent examiners at International Patent Offices (IPOs) can understand. The library is aimed at constructively organising TK and making it available in a format that can be easily disseminated. ${ }^{37}$ This has so far prevented the granting of wrong patents since TKDL serves as an accessible non-patent literature database that deals with traditional knowledge subject matter. ${ }^{38}$ In this regard TKDL is a good intervention, which can ensure the protection and preservation of TK. Access to TKDL agreements have been concluded with a number of international patent offices and TKDL evidence has been utilized to successfully challenge applications for patent registration, which utilized unmodified form TK that already forms part of the TKDL. ${ }^{39}$ In this sense, TKDL is used for defensive protection of TK. Defensive protection 'safeguards against illegitimate third-party assertion of IPRs over TK. ${ }^{29}$

Venezuela's Biozulua database contains data about medicinal plants and food crops, which are provided by twenty four ethnic groups living in the Amazonian jungle. The information has been availed in a database, which can be searched 'by species, geographical 
location, ethnic group or ailment. ${ }^{40}$ The project was established with a view to curbing biopiracy. This has been done by encouraging interested companies to contact the project's administrators instead of dealing directly with the indigenous groups. ${ }^{40}$

The approach in Venezuela can be used for fostering the procurement of informed consent and achieving broader engagement with the TK holders. Indigenous groups have however raised concerns over failure to procure their prior informed consent. ${ }^{41}$ These concerns imply that relations with the groups of TK holders should be dealt with properly once the databases are established and managed on their behalf.

A major limitation of creating databases is that the databases may be protected but not the information itself. For example, in the submission by the EU and its member states on TK and IPRs it was pointed out that 'the sui generis protection provided for in the EU legislation ${ }^{42}$ on the legal protection of databases covers the database itself, but not the actual information compiled therein.' Consequently, the EU and its member states suggested in their submission to the IGC, that 'patent offices... fully include TK in prior art searches, to the extent that this information is available to them. ${ }^{43}$

\section{Disclosure of origin and prior informed consent requirement in patent applications}

Disclosure of origin was proposed 'to restore trust in the patent system' and to 'prevent the granting of "bad"' patents' but opponents find this to be an extra burden on patent applicants in so far as it seems to be out of proportion with the problem that it seeks to solve. ${ }^{44}$

Article $8 \mathrm{j}$ of the Convention on Biological Diversity $(\mathrm{CBD})^{45}$ read together with Decision V/16, which was adopted at the Fifth Meeting of the Conference of the Parties to the CBD in $2000,{ }^{46}$ require that prior informed consent of TK holders be obtained before accessing their knowledge. Article $8 \mathrm{j}$ of the CBD provides that:

'Each party shall, as far as possible and as appropriate...

(j) Subject to its national legislation, respect, preserve and maintain knowledge, innovations and practices of indigenous and local communities embodying traditional lifestyles relevant for the conservation and sustainable use of biological diversity and promote their wider application with the approval and involvement of the holders of such 
knowledge, innovations and practices and encourage the equitable sharing of the benefits arising from the utilization of such knowledge, innovations and practices...'

In view of the fact that Article 8j does not clearly provide for the involvement of the TK holders and the steps to be taken for such an involvement are made subject to national legislation, Decision V/16 was adopted to specify that the TK holders' prior informed consent should be obtained. Decision V/16 requires, in principle, that access to traditional knowledge, innovations and practices of indigenous and local communities should be subject to prior informed consent or prior informed approval from the holders of such knowledge, innovations and practices. This specification still leaves the requirement of prior informed consent dependent on national legislation.

A number of countries have enacted national laws to include this requirement ${ }^{44}$ but a study on the impact of the disclosure of origin requirement has established that it has had limited impact in countries that have implemented the legislation. The study attributes this limited impact to two reasons; first, it is a relatively new requirement and secondly, it only affects national patent applicants. ${ }^{44}$

Requests to introduce disclosure of country of origin (of genetic resources in patent applications) have been made at two international forums: The African group submitted a request, to the sixth IGC session, for the introduction of 'a disclosure requirement in patent laws as well as evidence of compliance with national access and benefit sharing laws of the country of origin of genetic resources (disclosure of the source and country of origin of genetic resources in claimed inventions and the associated traditional knowledge used in invention). ${ }^{47}$ Brazil, Cuba, Ecuador, India, Pakistan, Peru, Thailand and Venezuela also requested that disclosure of origin of genetic resources be made mandatory under trade-related aspects of intellectual property rights (TRIPS) agreement. ${ }^{48}$

The above requests certainly touch on issues, ${ }^{49}$ which have generated debates in respect of which there are currently two camps with opposing views; first, that Article 27 of TRIPS provides finite conditions to be imposed on patent applicants. Consequently, introducing the requirement of disclosure of origin in national law as a condition for patentability would conflict with TRIPS. ${ }^{49}$ Secondly, Article 62 of TRIPS provides that member states can introduce reasonable procedures and formalities as long as they are consistent with the agreement. These 
arguments can be countered by reference to Article 29, which recognizes the requirement to disclose prior art by patent applicants. ${ }^{33}$ In this regard, Carvalho's argument that the inclusion of disclosure of origin in relation to genetic resources is not compatible with Article 27.1 of TRIPS agreement is correct to the extent that the previous requests for including this requirement were limited to genetic resources. The subsequent requests however also mentioned TK generally and as such the argument needs to be refocused. For instance, the fulfillment of the requirement of non-obviousness can certainly be raised in cases where unmodified forms of TK are patented and this would be compatible with TRIPS as it is a substantive requirement. The request by Brazil and other countries to the TRIPS council mentioned concerns about the quality of patent examination in cases relating to the neem tree, hoodia and ayahuasca. ${ }^{50}$ These cases are concerned with both genetic resources and traditional knowledge.

The idea behind including the requirement of prior informed consent (PIC) is to ensure that patent registration offices have 'evidence that rural communities were informed about the research and potential patent filings and had agreed to these issues beforehand'. ${ }^{51}$ Bibber-Klemm and colleagues have also argued that including this requirement would be the most effective instrument to ensure that TK is fully taken into account and acknowledged by patent applicants. They highlight the following benefits of including the requirement: ${ }^{33}$

- It would force patent applicants to double-check prior art;

- It would provide avenue for claims of benefit sharing or joint ownership;

- It would provide a legally binding mechanism to force patent applicants to show that the resources/knowledge they used as the basis for the invention was acquired with the consent of the individual or group concerned.

In view of the above benefits, the idea of broader negotiations with the communities does seem to find a place in the process of procuring informed consent from the communities. The requirement of PIC would equally work better with the creation of databases and registries if it is properly implemented with a view to avoiding the erosion of TK holders' culture. Databases are important for preserving culture. In this regard, they can perform a balancing act in so far as the IP needs can be taken care of and cultural preservation as well. This is evident from the 
objectives that countries that have documented their TK have in mind. Good examples of such countries are China, India and Venezuela.

\section{Joint inventorship}

There have been proposals to include TK holders as co-inventors as a way of ensuring protection and preservation of TK. ${ }^{52}$ The viability of TK holders claiming joint inventorship in patent applications may however be questionable. Bibber-Klemm and colleagues have, for instance, pointed out that the issue here is whether the contribution of the TK holders would be sufficient to enable them claim joint inventorship. ${ }^{33}$ They do however make the following valid point, which would be useful in providing some direction in attempting to protect TK through this means:

"In the case of traditional knowledge obtained with prior informed consent (which itself contains a statement by people accessing the knowledge concerning the use), normal patent rules can be relatively easily used to provide joint inventorship to traditional knowledge holders if their contribution is clearly linked and relevant to the final product". ${ }^{33}$

The above statement essentially calls for the consideration of each case on its own merits and as such it may not be viable to stipulate specific rules that cover all cases of TK holders who may wish to claim joint inventorship.

A well-documented case where a TK holder has been involved as a joint inventor is the Nigerian case, which involved the use of traditional medicine for the management of sickle cell disorder (SCD). The National Institute for Pharmaceutical Research and Development (NIPRD) received credible information about a traditional health practitioner (THP), Rev. Ogunyale, who was treating SCD patients with a herbal medicine' and discussed possible collaboration with him. ${ }^{53}$ NIPRD negotiated with the THP and 'he released his recipe, as a sacred trust, for further development into an effective medicine for the benefit of SCD patients globally. ${ }^{53}$ The parties agreed on a memorandum of understanding in terms of which the THP became a member of the research team, which improved the recipe at his clinic to develop a herbal medicine (NIPRISAN) and he was also included in the patent application as well as all publications. ${ }^{54}$ This case illustrates the fact that in order to protect TK using this avenue, each member of the collective group of TK holders should have contributed to the creation or invention. It may be difficult to 
satisfy this requirement in situations where the TK in question has been in existence for a considerable number of generations and it is the creation of an entire group.

\section{Introduction of petty patents}

Petty patents, which are also called utility models in some jurisdictions, require less detailed inventive steps and could therefore be more suitable for the protection of TK. ${ }^{13}$

Proponents of such patents argue that the shorter term of protection and the less stringent requirements are 'ideally suited for innovations that build upon existing innovations, without much original contribution' and would thus perform the important role of protecting these innovations from free riding. ${ }^{55}$ Petty patents may also be suitable for protecting value that individuals may add to $\mathrm{TK}^{56}$

\section{Directions for intellectual property and TK}

The efforts that have been made to protect and preserve TK are commendable though clear direction on how they can be used more effectively is necessary. Experience for mapping the way forward can be drawn from these efforts. The directions that are discussed in this part of the paper target policy making at both national and international levels since, as Verma accurately observes, 'for a holistic protection of TK, measures may be conceived at both the international and national levels. ${ }^{24}$ This observation is true because TK is currently used in a more globalized context, which warrants protection at an international level as well.

A good starting point in providing direction would be to consider the IGC's suggestions of understanding the interfaces between the formal IP system and customary legal systems, which apply to TK. Admittedly, this is not an easy task because, as Hansen and van Fleet have correctly observed, the IP regime's notion of individual ownership 'is often alien and can be detrimental to many local and indigenous communities. ${ }^{34}$ Cottier and Panizzon have observed that this alien notion has given rise to the view that 'IPRs would destroy traditions of free exchange and mutual communal support. ${ }^{56}$ This is evident, for instance, in Munzer and Raustiala's argument, which was mentioned earlier that 'the expansive protection of TK would, with some qualifications, remove what is now in the public domain from that domain. ${ }^{10}$ Cottier 
and Panizzon offer a very convincing argument, which can be used to counter the claim that IPRs over TK may destroy traditional ways of life:

'...the protection of collective rights is already well established in the existing international IP system. For example, trademark law protects collective marks. Communitarian rights of particular regions define geographical indications (GIs) and appellations of origins. Even the enforcement of copyrights and related rights has a long tradition of operating on the basis of collection societies to which authors and artists belong., 56

This argument implies that adjustments can be made to use the IP regime in a manner that maintains a balance between the protection and preservation of TK and the free exchange of knowledge.

One approach that has been suggested in current literature encompasses the use of property and liability regimes in the protection of TK. The property regime would vest exclusive rights on TK holders while the liability regime would allow third parties to use TK without prior authorization by the TK holders on the understanding that they compensate TK holders for use. ${ }^{12}$

The requirements of disclosing the origin of TK in patent applications and procurement of prior informed consent need to be addressed carefully. Hoare and Tarasofsky have argued that rather than including disclosure of origin as a requirement in patent applications, the solution to the granting of bad patents should be 'more stringent assessment of applications, with better prior art searching and more demanding inventive-step thresholds' ${ }^{4}$

The ideas of disclosure of origin and more stringent requirement would however work well together particularly with the ongoing documentation of TK and establishment of registries. The manner on which India and other countries that are mentioned in this article have used this means can serve as lessons for other countries. Hoare and Tarasofsky have proposed that the requirement of disclosure of origin 'should operate simply as a means to monitor the use of GRs [genetic resources], thus facilitating the enforcement of ABS legislation, or, alternatively, to assist patent offices with searches for prior art. ${ }^{, 44}$ This approach would however offer very weak protection for TK holders in view of the limitations of the created databases, which would still 
give rise to the possibility of bad patents being granted if the databases are not comprehensive enough and the patent applicant is not forthright enough to disclose prior art in the submitted application.

Another option has been suggested by Carvalho who argues that for purposes of avoiding possible conflicts with TRIPS agreement, World Trade Organization member states should make the enforceability of patent rights dependent on compliance with the requirement. ${ }^{49}$ This option could be used alongside Hoare and Tarasofsky's suggestion, which is mentioned above, with a view to ensuring better protection of TK holders' interests.

Suggestions that have been given in literature on factors that should be considered in developing a sui generis system of protection can be developed to protect TK should also be considered. The three factors that Dutfield has proposed are very relevant in this regard. ${ }^{12}$ First, registration of the rights should be encouraged as a way of fostering enforceability of the rights but it should not be made a legal requirement. This makes sense in view of the concern that has been noted in this paper that the current IP registration system is inaccessible and costly for TK holders. Secondly, the governments can determine the rights by law or a private collective management institution can be established to manage the rights. Thirdly, the envisaged sui generis system should take the world views and customary norms of TK holder communities into consideration since their customs regulate social and economic behavior. Notably, the IGC's draft Articles have incorporated this suggestion already in its 2012 version of the legal instrument.

The protection of TK is an evolving field that raises new issues and there are still ongoing debates in this field. As such, instead of providing ready-made answers to some of the issues, this article has raised more questions. The points that are mentioned in the article are however helpful for mapping the way forward for IP and TK, particularly at the policy making level.

\section{Acknowledgement}

I would like to thank the anonymous reviewers for their very helpful comments and also gratefully thank Hojjat Khademi, doctoral research fellow at the World Trade Institute, Bern (WTI) for his insightful comments during our discussions of earlier versions of this paper. I am equally grateful for the scholarship from Switzerland's State Secretariat for Economic Affairs (SECO)-funded cooperation project, which enabled me to prepare this paper while visiting as a research fellow at the WTI. 


\section{References}

${ }^{1}$ World Intellectual Property Organization, Intellectual Property and Traditional Cultural Expressions/Folklore (booklet no.1, WIPO publication number 913(E) date of publication unknown), p.19.

${ }^{2}$ Wendland W, Safeguarding Cultural Heritage, Protecting Intellectual Property and Respecting the Rights and Interests of Indigenous Communities: What Role for Museums, Archives and Libraries? Paper presented for the conference "Can Oral History Make Objects Speak?" Nafplion, Greece, October 18-21, 2005, p.2.

${ }^{3}$ Torsen M and Anderson J, Intellectual Property and the Safeguarding of Traditional Cultures: Legal Issues and Practical Options for Museums, Libraries and Archives (WIPO, Switzerland, Geneva) 2010, p.18.

${ }^{4}$ Correa CM, Access to knowledge: The case of indigenous and traditional knowledge in Krikorian G and Kapczynski A (eds) Access to knowledge in the age of intellectual property (Zone Books, New York), 2010, p.245.

${ }^{5}$ WIPO, Intergovernmental Committee on Intellectual Property and Genetic Resources, Traditional Knowledge and Folklore, Report, First Session, WIPO Doc. WIPO/GRTKF/IC/1/3 (March 16, 2001).

${ }^{6}$ WIPO Doc. WIPO/GRTKF/IC/1/3 (March 16, 2001), p.20; see footnotes 50 and 51.

${ }^{7}$ WIPO Intergovernmental Committee on Intellectual Property \& Genetic Resources, Traditional Knowledge \& Folklore, comparative summary of existing national sui generis measures and laws for the protection of traditional knowledge, $6^{\text {th }}$ Session., WIPO Doc. WIPO/GRTKF/IC/5/INF/4 (June 20, 2003).

${ }^{8} \mathrm{WO} / \mathrm{GA} / 26 / 6$ (August 25, 2000), paragraphs 14 and 23.

${ }^{9}$ Cullet P, Germann C, Nascimento AM and Pasadilla G, Intellectual property rights, genetic resources and traditional knowledge' in Biber-Klemm S and Cottier T (eds) Rights to plant genetic resources and traditional knowledge-basic issues and perspectives ( CABI, Wallingford, Oxfordshire ), 2005, p.142.

${ }^{10}$ Munzer SR and Raustiala K, The uneasy case for Intellectual Property Rights in Traditional Knowledge, Cardozo Arts \& Entertainment, 27(2009) 37-97.

${ }^{11}$ WIPO (2001) Intellectual Property Needs and Expectations of Traditional Knowledge Holders: WIPO Report on Fact-Finding Missions on Intellectual Property and Traditional Knowledge (1998-1999), p.57. (Hereinafter WIPO Report on Fact-Finding Missions, 2001).

${ }^{12}$ Dutfield G, Protecting Traditional Knowledge: Pathways to the Future (International Centre for Trade and Sustainable Development, Issue Paper No. 16, Geneva, Switzerland), 2006, p.22-32.

${ }^{13}$ Hansen SA and VanFleet JW, A Handbook on Issues and Options for Traditional Knowledge Holders in Protecting their Intellectual Property and Maintaining Biological Diversity (American Association for the Advancement of Science (AAAS), New York), 2003, p.24.

${ }^{14}$ Biber-Klemm S, Origin and allocation of Traditional Knowledge and landraces, in Biber-Klemm S and Cottier T (eds) Rights to plant genetic resources and traditional knowledge: basic issues and perspectives (CABI, Wallingford, Oxfordshire ), 2005, p.159ff.

${ }^{15}$ WIPO Doc. WIPO/GRTKF/IC/1/3 (March 16, 2001), p.22.

${ }^{16}$ Dutfield G, Intellectual property, biogenetic resources and traditional knowledge (Earthscan Publications, London), 2004, p.100-109. 
${ }^{17}$ CBD Secretariat (2009) Elements for the Development of Sui Generis Systems for Protection of Traditional Knowledge. UNEP/ CBD/WG8J/4/7, http://www.cbd.int/doc/meetings/tk/wg8j-05/information/wg8j-05-inf-16en.doc

${ }^{18}$ Gervais D, Traditional knowledge \& intellectual property: A TRIPS compatible approach, Michigan State Law Review, spring (2005) 137-166.

${ }^{19}$ I owe this observation to Hojjat Khademi, doctoral research fellow at the World Trade Institute, Bern.

${ }^{20}$ Cottier T and Panizzon M, A new generation of IPR for the Protection of Traditional knowledge in PGR for food, agricultural and pharmaceutical uses, in Biber-Klemm S and Cottier $\mathrm{T}$ (eds) Rights to plant genetic resources and traditional knowledge- basic issues and perspectives (CABI, Wallingford, Oxfordshire), 2005, p.205.

${ }^{21}$ Clemente Forero-Pineda, Scientific Research, Information Flows, and the Impact of Database Protection on Developing Countries, in Esanu JM and Uhilr PF (eds.), Open Access and the Public Domain in Digital Data and Information for Science: Proceedings of an International Symposium (Washington, D.C.: The National Academies Press), 2004, p.38.

${ }^{22}$ WIPO/GRTKF/IC/3/8 (March 29, 2002).

${ }^{23}$ See Intergovernmental Committee on Intellectual Property and Genetic Resources, Traditional Knowledge and Folklore, Second Session, Report, adopted by the Committee, WIPO document WIPO/GRTKF/IC/2/16, of December 14, 2001, at paragraph 17.

${ }^{24}$ Verma SK, Protecting Traditional Knowledge: Is a Sui generis System an Answer! The Journal of World Intellectual Property, 7 (2004) 765-805.

${ }^{25}$ Report of the fifth session, WIPO/GRTKF/IC/5/15 (August 4, 2003), paragraphs 19 and 29.

${ }^{26}$ WIPO/GRTKF/IC/21/4 (January 18, 2012). The draft was released on $20^{\text {th }}$ April 2012.

${ }^{27}$ IGC 19 Update: WIPO IGC Agrees to Extend and Strengthen Negotiating Mandate, Makes Substantive Progress on TK, TCEs and GRs, http://www.wipo.int/tk/en/news/2011/news_0019.html (18th May 2012).

${ }^{28}$ See articles 1 to 8 respectively.

${ }^{29}$ McManis C \& Teran Y, Trends \& scenarios in the legal protection of traditional knowledge, in Wong T \& Dutfield G (eds) Intellectual Property \& human development: current trends \& future scenarios (Cambridge University Press, Cambridge), 2011, p. 153.

${ }^{30}$ For developments in the African region, see Hinz MO, the Swakopmund Protocol on the Protection of Traditional Knowledge and Expressions of Folklore, Namibia Law Journal, 3(1) (2011) 101-112.

${ }^{31}$ Oseitutu JJ, A sui generis regime for traditional knowledge: the cultural divide in intellectual property law, the Marquette Intellectual Property Law Review, 15(1) (2011)147-215.

${ }^{32}$ WIPO Doc. WIPO/GRTKF/IC/1/3 (March 16, 2001), p.26.

${ }^{33}$ Biber-Klemm S, Cullet P, Germann C, Nascimento AM and Curci J, Flanking policies in national and international law, in Biber-Klemm S and Cottier T (eds) Rights to plant genetic resources and traditional knowledge- basic issues and perspectives (CABI, Wallingford, Oxfordshire ), 2005, p.241.

${ }^{34}$ Hansen SA and VanFleet JW, A Handbook on Issues and Options for Traditional Knowledge Holders in Protecting their Intellectual Property and Maintaining Biological Diversity (American Association for the Advancement of Science (AAAS), New York), 2003, p.24. 
${ }^{35}$ Liu Y and Sun Y, China Traditional Chinese Medicine (TCM) Patent Database, World Patent Information, 26 (2004) 91-96.

${ }^{36}$ About TKDL, http://www.tkdl.res.in/tkdl/langdefault/common/Abouttkdl.asp?GL=Eng (21 May 2012).

${ }^{37}$ Jeevan VKJ, Digital library development: identifying sources of content for developing countries with special reference to India, the International Information \& Library Review, 36(2004) 185-197.

${ }^{38}$ Gupta VK, Traditional Knowledge Digital Library, paper presented at the Sub-Regional Experts Meeting in Asia on Intangible Cultural Heritage: Safeguarding and Inventory-Making Methodologies (Bangkok, Thailand, 13-16 December 2005).

${ }^{39}$ For specific examples, see http://www.tkdl.res.in/tkdl/langdefault/common/Abouttkdl.asp?GL=Eng

${ }^{40}$ Owain J, Venezuelan project establishes indigenous plant database, British Medical Journal, 325 (27 July) (2002) 183.

${ }^{41}$ Ruiz M, Lapeña I and Clark SE, The protection of traditional knowledge in Peru: a comparative perspective, Washington University Global Studies Law Review, 3 (2004) 755-797.

${ }^{42}$ Directive 96/9/EC on the legal protection of databases, OJ No L 77 of 27.3.1996, p.20.

${ }^{43}$ WIPO Intergovernmental Committee on Intellectual Property \& Genetic Resources, Traditional Knowledge \& Folklore, Report, $3^{\text {rd }}$ Session, WIPO Doc. WIPO/GRTKF/IC/3/16 (June 14, 2002).

${ }^{44}$ Hoare LA and Tarasofsky GR, Asking and Telling: Can "Disclosure of Origin" Requirements in Patent Applications Make a Difference? The Journal of World Intellectual Property, 10(2) (2007)149-169.

${ }^{45}$ United Nations, Convention on Biological Diversity, 1992, http://www.cbd.int/doc/legal/cbd-en.pdf

${ }^{46}$ COP 5 Decision V/16, http://www.cbd.int/decision/cop/?id=7158

${ }^{47}$ WIPO Intergovernmental Committee on Intellectual Property \& Genetic Resources, Traditional Knowledge \& Folklore, Submission by the African group: objectives, principles and elements of an international instrument, or instruments, on intellectual property in relation to genetic resources and on the protection of traditional knowledge and folklore, $6^{\text {th }}$ Session., WIPO Doc. WIPO/GRTKF/IC/6/12 (March 15, 2004).

${ }^{48}$ World Trade Organization, council for Trade-Related Aspects of Intellectual Property Rights. Elements of the obligation to disclose the source and country of origin of the biological resources and/or traditional knowledge used in an invention (Submission from Brazil, Cuba, Ecuador, India, Pakistan, Peru, Thailand, and Venezuela). WTO IP/C/W/429/Rev.1 (27 September 2004).

${ }^{49}$ Carvalho NP, Requiring disclosure of Origin of genetic resources and prior informed consent in patent applications without infringing the TRIPS Agreement: the problem and the solution, Washington University Journal of Law and Policy, 2(2000) 371-401. At page 379, Carvalho identifies the relevant issues as having to do with a possible conflict between introducing the requirement of origin and the following relevant articles of the TRIPS agreement, which provide for substantive requirements for patentability: Article 27.1 on patentable subject-matter; 29 on conditions that may be imposed on patent applicants; 62 on acquisition and maintenance of intellectual property rights and related inter partes procedure and 32 on revocation and forfeiture of patents.

\footnotetext{
${ }^{50}$ See paragraphs 3-6 of submission to WTO (WTO IP/C/W/429/Rev.1 (27 September 2004))

${ }^{51}$ Mahop MT, Intellectual property, community rights and human rights: the biological and genetic resources of developing countries (Routledge, London), 2010, p. 123.
} 
${ }^{52}$ See Huft JM, Comment, Indigenous Peoples and Drug Discovery Research: A Question of Intellectual Property Rights, Northwestern University Law Review, 89(1995) 1678-1730 at 1722; Gupta KA, Rewarding Creativity for Conserving Diversity in [the] Third World: Can IPR Regimes Serve the Needs of Contemporary and Traditional Knowledge Experts in [the] Third World? http://www.sristi.org/papers/instar.htm

${ }^{53}$ Wambebe, Charles (2007) NIPRISAN Case, Nigeria. A Report for GenBenefit. http://www.uclan.ac.uk/schools/school_of_health/research_projects/files/health_genbenefit_nigerian_case.pdf

${ }^{54}$ GenBenefit (Benefit sharing with developing countries), Benefit Sharing- Lessons learned: A Summary and crosscomparison of the Case Studies for GenBenefit (2008), p.12. Available at http://www.uclan.ac.uk/schools/school_of_health/research_projects/files/health_genbenefit_lessons.pdf

${ }^{55}$ Srinivas KR, Traditional Knowledge and Intellectual Property Rights: A Note on Issues, Some Solutions and Some Suggestions, Asian Journal of WTO \& International Health Law and Policy, 3(1) (2008) 81-120.

${ }^{56}$ Cottier T and Panizzon M, Legal perspectives on traditional knowledge: the case for intellectual property rights protection, Journal of International Economic Law, 7(2) (2004) 371-400. 